\title{
Social Interpersonal Skills of Handicapped and Nonhandicapped Adults at Work
}

\author{
BENJAMIN LIGNUGARIS/KRAFT \\ CHARLES L. SALZBERG \\ JOSEPH J. STOWITSCHEK
}

The pattern and content of social interactions of successful handicapped and nonhandi-
capped employees were observed in two employment settings. Data suggest that both groups
were active social interactants who frequently worked cooperatively, yet interacted relatively
infrequently with their supervisors. Implications for future research are discussed.

It has been suggested in

critical factor in the sun recent research that social behavior at work is a disabled individuals (Fuccessful vocational habilitation of developmentally LaGreca, Stone, \& Bell, 1982; Agran, \& Lignugaris/Kraft, in; Melstrom, 1982; Rusch, 1979; Salzberg, Lignugaris/Kraft, in press-b; Sress-a; Salzberg, Likins, McConaughy, \& Bostwick (1981) surveyed rehabilitation \& Harper, 1978). Foss and mentally disabled rehabilitation clitation service providers and developcommunity integration of devion clients to identify major problems in the interpersonal skills were the developmentally disabled adults. Social and and were a major emplo largest single category of problems identified mployment concern of both service providers and

uch as poor relationships revealed that deficient interpersonal skills, with job performance and supervisors and co-workers, may interfere Peterson, 1981; Mathews, Whangicantly affect job retention (Foss \& 1978; Wehman, 1981). To hang, \& Fawcett, 1981; Schalock \& Harper, able to interact competently successful at work, individuals need to be cases, with customers, as well as supervisors, co-workers, and, in some tasks.

\footnotetext{
Benjamin Lignugaris/Kraft is a research assistant, Social Protocol Resea Handicapped Persons, Charles L. Salzberg is a profe University, Logan. Sarah Rule with the Developmental Center for research was supported by Grant \#epartment of Special Educ is a research associate professor and wish to thank Martin Agran for \#G008103899 from the Offication, Utah State University. This gran for his critical feedback on early drafts of thial Education. The authors 
Although refined technology is available to help developmentally disabled adults learn tasks related to production (i.e., Bellamy, Peterson, \& Close, 1975; Gold, 1976; Irvin \& Bellamy, 1977), little research has been devoted to examining social relationships in the workplace (Halpern, Browning, \& Brunner, 1975). Research on social skills related to employment has generally been limited to maladaptive behaviors that impair a worker's chances for gaining and maintaining employment. In one study, LaGreca et al. (1982) observed four employees in a sheltered workshop and seven students in a prevocational classroom. These observations were used in conjunction with interviews of service providers to compile a list of common problems in vocational workshops. In other studies procedures to reduce noncompliance and complaining (Connis \& Rusch, 1980; Schutz, Rusch, \& Lamson, 1979), inappropriate touching (Matson \& Martin, 1979), and topic repetition (Rusch, Weithers, Menchetti, \& Schutz, 1980) have been investigated.

Examinations of prosocial work behavior have been limited largely to sheltered work settings (Johnson \& Mithaug, 1978; Mithaug \& Hagmeier, 1978; Mithaug, Hagmeier, \& Haring, 1977). In these studies, the staff of sheltered workshops have been asked to identify the social and task repertoires necessary for mentally retarded individuals to enter and retain sheltered employment. In one of the few observational studies in which the social behavior of developmentally disabled adults was examined, Berkson and Romer (1980) described the social interactions of workers during coffee breaks and lunch in four sheltered workshops. Individuals were observed engaging primarily in paired interactions that focused on conversation and on eating or drinking.

Although the work of Berkson and his colleagues (Berkson \& Romer, 1980; Romer \& Berkson, 1981) has begun to shed light on the interpersonal repertoires of developmentally disabled adults in sheltered work settings, the social skills needed for employment in most work settings remain largely unexplained. The few studies in competitive work settings have focused on employers' expectations of their workers (Buehler, 1969; Langford \& Salzberg, 1982; Rusch, Schutz, \& Agran, 1982; Salzberg et al., in press-a).

The purpose of this study was to describe selected aspects of social behavior of successful handicapped and nonhandicapped employees at work. The pattern and some aspects of the content of the social interactions among these workers were examined.

\section{METHOD}

\section{Participants}

Handicapped $(n=17)$ and nonhandicapped $(n=16)$ individuals were observed in two work sites. According to their employment records, the 
handicapped participants were mildly to moderately retarded. (In most cases this determination was based on IQ scores or on scores from the American Association on Mental Deficiency's (AAMD) Adaptive Behavior Scale (Lambert, Windmiller, Tharinger, \& Cole, 1981) although in some cases, the basis of the diagnosis was not specific.) They ranged in age from 21 to 62 years old $(M=36)$ and lived either independently in apartments $(n=11)$ or with their families $(n=5)$ (i.e., parents, a brother, or a sister). These individuals had been working for their present employers for an average of 4.6 years with a range of 6 months to 18 years.

The nonhandicapped participants either lived independently $(n=13)$ or with their families $(n=3)$. They ranged from 21 to 84 years old $(M=61)$ and had been working for their present employers for a mean of 5.7 years with a range of 4 months to 17.5 years.

\section{Setting}

Observations took place at two large companies that specialize in refurbishing household goods. A primary purpose of these nonprofit businesses is to employ some individuals who might otherwise have difficulty finding work; thus, a large proportion of the workers are handicapped or elderly. In this respect, the work environment may differ from other competitive work situations. These businesses, however, are unlike sheltered workshops. They are considerably more selective in their hiring processes, employees earn at least the minimum wage, employees must meet rigorous production standards with intensive supervision, and employees who do not perform satisfactorily are fired. Thus, the term nomprofit business is used throughout this article, although in most ways, these settings seemed more like competitive employment situations than
sheltered workshops.

Workers performed various tasks such as loading and unloading trucks, working at stationary benches or tables (e.g., refurbishing shoes, cleaning merchandise, fixing or repairing goods, assembling furniture, and sorting clothes), or pricing goods. Employees were observed both in the mornings
and afternoons.

\section{Procedure}

Recording. Each participant was observed for a minimum of 60 minutes in 5- to 10-minute periods. After each observation, the participants' social interactions were described using a social behavior checklist.

content of interactiocklist included 35 questions about the pattern and given target participant (Sccurred during the observation period for a partly on behaviors found to bendix A). The questions were based search (Berkson \& Romer, Stowitschek, \& Rule, 1983) 1980; Foss \& Peterson, 1981; Salzberg, about specific patterns of and the need to obtain information 
trainers considered valuable in the vocational preparation of the developmentally disabled. Several questions referred to whether conversations were work related or nonwork related (See Appendix A, II-A), whether interactions included cooperation (II-B) or criticism (II-C) either to or by the participant, and whether others were interacting at times when the target participant interacted very little (II-F).

Observers recorded "yes" when the situation occurred at least once during the observation, "no" when the situation never occurred during the observation, and "don't know" when they were unsure whether the situation had occurred. In some cases, a question was not applicable in a given observation. For example, when the observer indicated that the supervisor was not present, questions referring to interactions between the supervisor and participant were not applicable. Nonapplicable questions were excluded from data analysis.

Observer training. The observers participated in two phases of training. In the first phase, they learned to use the social behavior checklist by observing videotaped work situations and recording workers' social interactions. In the second phase, observers recorded workers' interactions in actual employment settings. A training criterion of $80 \%$ agreement for two consecutive observation sessions in an employment setting was required.

Orientation. Before data collection, a minimum 2-week orientation procedure was conducted for each participant. First, potential participants were told about the project and asked to participate. After obtaining informed consent from the participants, trial observations were conducted to help them adjust to the observation process. Each worker was observed for 5 to 10 minutes at a time. Actual data collection began after a minimum of three trial observations.

\section{Reliability}

Interobserver agreement was assessed by a second observer, who simultaneously, but independently, observed and recorded the social interactions of employees. Reliability observations were conducted for approximately $30 \%$ of all observations across participants, settings, and times of day.

Reliability was calculated for each observation by dividing the number of agreements on each checklist by agreements plus disagreements and multiplying the dividend by 100 . Questions with responses of "don't know" or "not applicable" were excluded from the calculation to prevent the possibility of an artificially high agreement score. The mean interobserver agreement was $93 \%$ with a range of $76 \%$ to $100 \%$.

\section{RESULTS}

Both the extent of the employees' interactions with supervisors and coworkers and the general content of their conversations were examined 
using the checklist data. The first 12 items in Table 1 reflect th employees' interactions with their supervisors and co-workers.

The mean percentage and standard deviation of "yes" responses on th checklist was calculated by dividing the total number of "yes" response across all the observations by the total number of "yes" plus "no responses for each participant.

\section{TABLE 1}

\section{Participants and Content of Social Interactions}

\section{Participants in social interactions}

Was supervisor present?

Was co-worker(s) present?

Did the target subject talk to the supervisor or a co-worker?

Did the target subject and supervisor talk?

Did the target subject talk only to the supervisor? Did the supervisor talk with the target subject and/or another
worker?

Did the supervisor talk only to the target subject?

Did the supervisor talk only to some other than the target subject? subject?

Did the target subject talk with a peer or co-worker?

Did the target subject talk only to a co-worker?

Content of social interactions

\begin{tabular}{l}
$\begin{array}{c}\text { Observations } \\
\text { with } \\
\text { "Yes" response }\end{array}$ \\
\hline$M \quad$ SD
\end{tabular}

Did the target subject

Did the target subject talk on/y about a related topic?

Did the target subject talk about a nonwork-related topic?

Did the target subject talk only about a nork-related subject?

Did the target subject ask for help?
Did the target subject criticize nonwork-related subject?

Did the target subject verbally anyone?

If the target subject only tally joke or laugh?

target subject ask for help, criticize a work-related topic, did the

Did the supervisor criticize the target subje, or joke and laugh?

Did a peer criticize the target subject? subject?

Did others verbally joke or laughect?

Did the target subject receive his?

Did the target subject receive help?

Did the supervisor give individual help to the cooperatively?

Did the supervisor give individual help to the target subject?

target subject?

Did the target subject give help or work cooperatively with peers?
Did the target subject engage in roughhousing

Did others engage in roughhousing?

Did the target subject sit or stand

or standing in groups? 
Participants were almost always working in situations in which there were opportunities for interactions. At most stations, two or more employees worked side by side. Because the work was done with the hands and did not usually require continuous concentration, workers were able to talk freely while they worked. Supervisors were present during approximately two-thirds of the observations.

In general, the employees were active interactants. They conversed with supervisors or co-workers during $85 \%$ of the observations in which a supervisor or co-worker was present. Participants interacted with coworkers in approximately four-fifths of the observations. In two-thirds of the observations, they conversed exclusively with co-workers.

Employees interacted with supervisors during only $6 \%$ of the observations in which supervisors were present. Supervisors interacted with other workers near the target participant in $77 \%$ of the observations, and, in $45 \%$ of the observations for each participant, the supervisor interacted with other nearby workers but not with the target participants.

These data suggest that (a) workers were frequent interactants who conversed more with co-workers than with supervisors; and (b) there was considerable variation across work stations, participants, and time (note the large standard deviations in Table 1).

The content of the participants' social interactions is also recorded in Table 1 . The content questions on the checklist reflected (a) whether interactions were work related or nonwork related; (b) the extent to which participants requested assistance, criticized others, and joked with coworkers; and (c) the context in which the interactions took place.

Conversations included work-related topics (reference to job or objects within the work environment) in $85 \%$ of the observations. In two-thirds of the observations, conversation was exclusively work related. In these conversations, requesting help, criticizing others' work, or joking about a work-related topic occurred in $40 \%$ of the observations. A smaller proportion of observations included nonwork-related conversation $(\bar{X}>=30 \%)$. Only $6 \%$ of the observations for each participant included conversations that were exclusively nonwork related.

Workers rarely requested assistance or criticized others. Joking among workers was common $(\overline{\mathrm{X}}>=29 \%)$. The only statistically significant differences between handicapped and nonhandicapped workers were in the mean proportion of observations per participant in which handicapped and nonhandicapped participants joked and laughed or their co-workers joked and laughed $(t=2.20, p<.05$ for participants; $t=2.11, p<.05$ for coworkers).

Although target participants rarely requested assistance, they helped or worked cooperatively with co-workers during approximately threefourths of the observations. Supervisors assisted workers about $30 \%$ of the time. No workers were observed engaging in inappropriate physical or verbal behaviors such as throwing objects or cursing. In addition, none 
of the workers observed tended to isolate themselves. Participants were alone when others were in groups during only $4 \%$ of the observations.

Thus, individuals in these work settings were highly social. Conversations were frequent and generally about work-related topics. Requests for assistance and criticisms of others were infrequent, whereas giving assistance and working cooperatively were very frequent. Both groups of participants interacted frequently with co-workers, but nonhandicapped workers laughed and joked significantly more often. The amount of supervisory assistance was the same for handicapped and nonhandicapped workers.

\section{DISCUSSION}

In this study, social interactions among handicapped and nonhandicapped workers in nonprofit work settings were examined. The data suggest that both the patterns and the content of interactions were similar for handicapped and nonhandicapped workers who had been employed for an average of 4 to 5 years. The emerging pattern of interaction reflects frequent interaction among co-workers, whereas interaction with supervisors was relatively infrequent. Social patterns, however, might some work situatio across different business environments. Moreover, in multiple, delayed insts specific types of social interaction, such as following might be more difficult for or handling criticism, may be required that handicapped workers.
In settings

In settings that require more frequent supervisory assistance, differen-
tial attention might be examined in this study, to handicapped workers. In the businesses numbers of workers throughout supervisors were responsbile for large could not interact extensivelyout an extensive work setting; thus, they that include examination of with individual workers. Descriptive studies workers might production of supervisors who monitor smaller numbers of Although the workers different findings.

half as much with supervisors as in this study interacted approximately interactions with supervisors as with co-workers, it is possible that their attempt was made to evaluate were critical to success on the job. No Peterson (1981), however, reported types of interactions. Foss and and supervisors were of peported that relationships between workers

A number of social and vocation concern to placement personnel. Independent (Appoloni \& Westaway training programs such as Becoming and Pathways Toward Independence (The , Don't Get Fired (Anema, 1979), important work skills such as seekin (The Nisonger Center, 1979) address Few programs, however, address cossistance and accepting criticism. important in establishing positive relanversational skills that might be workers. The conversations of the rationships with supervisors and $c^{-}$

JOURNAL OF EMPLOYMENT COUNSELING 
study were principally work related. If individuals were taught some minimal job-related conversational repertoires, they might be better prepared to socially adapt and retain employment. Additional research examining the relationship between conversational skills and job success is needed.

Results indicated that nonhandicapped workers laughed and joked more often than did handicapped workers. A sense of humor may not be a critical attribute of successful employees; however, it may play a role in developing positive co-worker relationships. An examination of whether differences in humor displayed on the job correspond to differences in patterns of interaction off the job might be beneficial. Conversations before work and during breaks might include more humor and less workrelated topics than conversations during work. If so, handicapped workers may be at a disadvantage in those situations. Research is needed to determine the frequency of different types of verbal statements and to relate the importance of behaviors such as commands, requests, or informational statements to successful interaction at work. Such information could have direct implications for employment counselors who are responsible for teaching prosocial vocational skills to handicapped individuals.

Because observational research in business settings is relatively rare, the process of observation may affect the character of the interactions being observed. To minimize the effects of a potentially intrusive observation system, we employed a carefully selected set of procedures for a 2-week period to help the participants adjust to being observed. The frequent joking that occurred during observations indicated that most participants were not unduly intimidated by the observers; however, it is possible that some types of social interaction, especially nonwork-related conversation, criticism, roughhousing, or inappropriate behavior, may have been suppressed because of their presence. Similarly, supervisors may have been more likely to avoid workers when they were being observed.

This study focused on social interactions during work. As already suggested, it is important that workers know how to interact effectively during coffee breaks or lunch. Berkson and Romer (1980) examined social interactions during breaks and lunch in a sheltered work setting. Similar observational studies conducted in competitive job sites are needed to determine the parameters of social behavior required in competitive work situations.

This research provides a basis for the empirical identification of the pattern and content of social interactions among successful handicapped individuals in work settings. The work sites examined in this study contained extensive social and cooperative behavior. Similar research in various work settings is needed to pinpoint patterns of interaction that are common across businesses. In addition, a more detailed analysis of the 
content of conversation during work and during breaks is needed to target specific prosocial behaviors for employment training.

\section{REFERENCES}

Anema, D. (1979). Don't get fired. Hayward, CA: Janus,

Appolloni, T., \& Westaway, A. (1978). Becoming independent. Bellevue, WA: Edmark.

Bellamy, G.T., Peterson, L., \& Close, D. (1975). Habilitation of the severely and profoundly retarded: Illustrations of competence. Education and Training of the Mentally Retarded, 10, 174-186.

Berkson, G., \& Romer, D. (1980). Social ecology of supervised communal facilities for mentally disabled adults: I. Introduction. American Journal of Mental Deficiency, 85, 219-

Buehler, R.E. (1969). Job-related behavior rating scale. Training and Development Journal, 23, 14-20.

Connis, R.T., \& Rusch, F.R. (1980). Programming maintenance through sequential with drawal of social contingencies. Behavior Research of Severe Developmental Disabilities, 1 ,
246-260.

Foss, G., \& Bostwick, D. (1981). Problems of mentally retarded adults: A study of rehabilitation service consumers and providers. Rehabilitation Counseling Bulletin, 25, 66-
73 .

Foss, G., \& Peterson, S. (1981). Social-interpersonal skills relevant to job tenure for mentally retarded adults. Mental Retardation, 19, 103-106.

Gold, M.W. (1976). Task analysis of a complex assembly task by the retarded blind Exceptional Children, 43, 78-84.

Greenspan, S., \& Shoultz, B. (1981). Why mentally retarded adults lose their jobs: Social competence as a factor in work adjustment. Applied Research in Mental Retardation, 2, 23-

Halpern, A., Browning, P.L., \& Brunner, E.R. (1975). Vocational adjustment of the mentally retarded. In M.J. Begab \& S.A. Richardson (Eds.), The mentally retarded and society: A social science perspective (pp. 365-376). Baltimore: University Park Press.

Irvin, L.K., \& Bellamy, B.T. (1977). Manipulation of stimulus features in vocational skil training of the severely retarded. American Journal of Mental Deficiency, 81, 486-491.

Johnson, J.L., \& Mithaug, D.E. (1978). A replication of sheltered workshop entry require ments. AAESPH Review, 3, 116-122.

Lambert, N., Windmiller,

Scale school edition. M., Tharinger, D., \& Cole, L. (1981). AAMD Adaptive Behavior

Langford, C., \& Salzberg, C.L

restaurants. Unpublished (1982). Developing socially valid teaching targets for fast food Education. (Available from

LeGreca, A.M., Stone, W.L., \& B.L. Salzberg at the university.) skills of mentally retarded individ.R. (1982). Assessing the problematic interpersonal Retardation, 3, 37-53.
Mathews,

skills. Journal of Employment Cowcett, S.B. (1981). Behavioral assessment of job-related

Matson, J.L., \& Martin, Joyment Counseling, 18, 3-12.

severely retarded. Journal of Mental

Melstrom, M.A. (1982). Social ecology Deficiency Research, 23, 9-16. disabled adults: 7. Productivity and of supervised communal facilities for mentall of Mental Deficiency, 87, 40-47.

Mithaug, D.E., \& Hagme

prevocational competencies of (1978). The development of procedures to assess 94-115. 
Mithaug, D.E., Hagmeier, L.D., \& Haring, N.G. (1977). The relationship between training activities and job placement in vocational education of the severely and profoundly handicapped. AAESPH Review, 2, 89-109.

he Nisonger Center. (1975). Pathways toward independence. Columbus, OH: Ohio State University.

omer, D., \& Berkson, G. (1981). Social ecology of supervised communal facilities for mentally disabled adults: 4 . Characteristics of social behavior. American Journal of Mental Deficiency, 86, 28-38.

usch, F.R. (1979). Toward the validation of social/vocational survival skills. Mental Retardation, 17, 143-144.

usch, F.R., Schutz, R.P., \& Agran, M. (1982). Validating entry-level survival skills for service occupations: Implications for curriculum development. Journal of the Association for the Severely Handicapped, 8, 32-41.

usch, F.R., Weithers, J.A., Menchetti, B.M., \& Schutz, R.P. (1980). Social validation of a program to reduce topic repetition in a non-sheltered setting. Education and Training of the Mentally Retarded, 15, 208-215.

alzberg, C.L., Stowitschek, J.J., \& Rule, S. (1983, September). Methodological issues in research on vocationally related social behavior. Paper presented at the annual meeting of the Midwestern Educational Research Association, Kansas City, MO.

alzberg, C.L., Agran, M., \& Lignugaris/Kraft, B. (in press-a). Behaviors that contribute to entry-level employment: A profile of five jobs. Applied Research in Mental Retardation.

laberg, C.L., Likins, M., McConaughy, E.K., \& Lignugaris/Kraft, B. (in press-b). Social competence and employment of retarded persons. In N.R. Ellis \& N.W. Bray (Eds.), International Review of Research in Mental Retardation. New York: Academic Press.

halock, R.L., \& Harper, R.S. (1978). Placement from community-based mental retardation programs: How well do clients do? American Journal of Mental Deficiency, 83, 240247.

hutz, R.P., Rusch, F.R., \& Lamson, D.S. (1979). Eliminating unacceptable behavior: Evaluation of an employer's procedure to eliminate unacceptable behavior on the job. Community Services Forum, 1, 4-5.

ehmen, P. (1981). Competitive employment: New horizons for severely disabled individuals. Baltimore: Paul H. Brookes.

\section{APPENDIX A}

\section{Field Observation Checklist}

Participants in social interactions

A. Did the target participant and supervisor talk?

B. Did the supervisor talk to someone other than the target participant?

C. Did the target participant talk with a peer or co-worker?

D. Did the target participant talk with two or more co-workers?

E. Was the supervisor present?

F. Were co-workers(s) present?

Content of social interactions

A. General content

1. Did the target participant talk about a work-related topic? 
2. Did the target participant talk about a nonwork-related topic?

B. Cooperation, helping, and sharing

1. Did the target participant give help or work cooperatively with peers?

2. Did the target participant ask for help?

3. Did the target participant receive help?

4. Did the target participant refuse to help or refuse to work cooperatively?

5. Did the supervisor give individual help to the target participant?

6. Did the supervisor give individual help to someone besides the target participant?

C. Criticism

1. Did the supervisor criticize the target participant?

2. Did a peer criticize the target participant?

3. Did the target participant criticize anyone?

D. Kidding around

1. Did the target participant engage in roughhousing?

2. Did others engage in roughhousing?

3. Did the target participant make verbal jokes or laugh?

4. Did others make verbal jokes or laugh?

E. Inappropriate behavior

1. Did the target participant engage in physical behavior that was grossly inappropriate?

2. Did others engage in physical behavior that was grossly inappropriate?

3. Did the target participant engage in bizarre verbal behavior?

4. Did others engage in bizarre behavior?

5. Did the target participant interrupt a

6. Did anyone interrupt interrupt a conversation?

7. Did the target part the target participant? anyone around?

8. Did a co-wo around?

10. Did the target participant throw things or destroy property?

11. Did the target things or destroy property? language?

12. Did others curse, swear, or use profane language?

2. Did the target participant did not talk, were others talking? were sitting or participant sit or stand alone while others 